\title{
Adenovirus-Mediated Expression of BMP- 2 and BFGF in Bone Marrow Mesenchymal Stem Cells Combined with Demineralized Bone Matrix For Repair of Femoral Head Osteonecrosis in Beagle Dogs
}

\author{
Wu-Xun Peng ${ }^{\mathrm{a}} \quad$ Lei Wang ${ }^{\mathrm{b}}$ \\ a Department of Traumatic Orthopedics, The Affiliated Hospital of Guizhou Medical University, Guiyang, \\ ${ }^{b}$ Department of Statistics, Guizhou Health Information Center, Guiyang, P.R. China
}

\section{Key Words}

Osteonecrosis of the femoral head - Bone marrow mesenchymal stem cells - Bone morphogenetic protein 2 - Basic fibroblast growth factor $•$ Demineralized bone matrix

\begin{abstract}
Background: This study investigated the effect of using adenovirus-mediated expression of bone morphogenetic protein 2 (Ad-BMP-2) and basic fibroblast growth factor (bFGF) in bone marrow mesenchymal stem cells (BMSCs) in combination with a demineralized bone matrix (DBM) to repair osteonecrosis of the femoral head (ONFH) in Beagle dogs. Methods: A total of 30 Beagle dogs were selected for the isolation of BMSCs, which were cultured and transfected with the recombinant adenovirus vector Ad-BMP2-bFGF-GFP (carrying BMP-2 and bFGF) or a control adenovirus plasmid (encoding green fluorescent protein (Ad-GFP)). The expression of the transfected BMP-2 and bFGF proteins was detected by Western blotting. After transfection, the BMSCs were induced to undergo osteoblastic differentiation. The DBM was prepared to construct a DBM/BMSC complex. Beagle models of canine femoral head defects and necrosis were established and divided into control, DBM, DBM/BMSC, vector Ad-BMP2-bFGF-GFP and Ad-GFP groups. The composite graft was then implanted, and new bone morphology was visualized via X-ray at 3,6 and 12 weeks after the operation. Hematoxylin and eosin (HE) staining and Masson's trichrome staining were used to identify new bone formation. Immunohistochemistry was performed to calculate the density of new blood vessels. The compressive and bending strength of the BMSCs was evaluated at 12 weeks after the operation. Results: BMSCs were successfully isolated. The protein expression of BMP-2 and bFGF was significantly higher in the Ad-BMP-2/bFGF group than the normal and Ad-GFP groups. Compared with the control group, at 12 weeks after the operation, the DBM, DBM/BMSC, vector Ad-BMP2-bFGF-GFP and Ad-GFP groups showed a larger area of new bone, higher $\mathrm{X}$-ray scores, greater neovascularization density, and increased compressive


and bending strength. The most significant modifications occurred in thevector Ad-BMP2bFGF-GFP group. Conclusion: The results indicate that the use of Ad-BMP-2/bFGF-modified BMSCs in conjunction with DBM could successfully repair ONFH in a dog model by promoting bone formation and angiogenesis.

\section{Introduction}

Osteonecrosis of the femoral head (ONFH) is a common condition in young adults and is generally refractory to treatment. The pathogenesis mechanism for ONFH is poorly understood [1], despite that the incidence of the condition is increasing with the rapid economic development in many countries [2]. As ONFH progresses, it can eventually result in femoral head collapse and degenerative changes to the hip joint if effective treatment is not implemented [3]. Various surgical procedures, including core decompression [4] and various types of osteotomies [5], have been used to maintain femoral head stability and to avoid unpredictable results in younger patients [6]; however, despite some progress, effective treatment for ONFH remains a challenge [7].

Cell therapy has recently emerged as a potential regenerative treatment [8]. Mesenchymal stem cells (MSCs) have the capacity for self-replication, differentiation, and regeneration [9]. Among MSCs, bone marrow mesenchymal stem cells (BMSCs) have vast potential for tissue engineering as well as regenerative medicine [10]. The injection of MSCs, such as BMSCs, into the femoral head has been proven effective for treating osteoarticular disease [11]. Demineralized bone matrix (DBM), composed of bones in which the mineralized portion has been removed while maintaining the organic matrix and growth factors [12]. It is frequently used for bone repair because of its osteoinductivity [13]. Bone morphogenetic proteins (BMPs) are gaining attention in the area of bone repair due to their capacity for auto-induction [14]; they can induce the differentiation of MSCs under some culture conditions [15]. BMP2 , one of the most effective osteoinductive proteins, facilitates osteoblast differentiation, and prior studies have demonstrated that bone repair can be accomplished through the application of BMP-2 $[14,16]$. Basic fibroblast growth factor (bFGF) has important roles in a wide variety of cellular functions, including cell multiplication and angiogenesis [17], and due to its effects on gene expression and angiogenesis, it is a key factor during bone repair [18]. Adenovirus vectors have proven to be potent gene delivery vehicles that can be used to genetically manipulate cells [19]. Genetic manipulation of MSCs requires highly efficient gene delivery, and recombinant adenovirus has been extensively used as a gene transfer vector in this context [20]. Although both BMP2 and bFGF play important roles in bone repair, few studies have studied the efficacy of using recombinant adenovirus to deliver these proteins to treat ONFH. Therefore, this study aimed to investigate the role of Ad-BMP-2/bFGF-modified BMSCs combined with DBM in the repair of ONFH.

\section{Materials and Methods}

\section{Ethics statement}

Experiments were conducted under uniform conditions in our institutional animal laboratory and were approved by the Affiliated Hospital of Guizhou Medical University and Guizhou Health Information Center.

\section{Isolation of BMSCs from Beagle dogs}

Thirty Beagle dogs (animal permit no: SCXKG2008-0002; age: 6 months; weight: 8-12 kg; no gender restriction) were obtained from the Affiliated Hospital of Guizhou Medical University and Guizhou Health Information Center. All dogs were intravenously pre-medicated with $3 \%$ pentobarbital sodium $(1 \mathrm{~mL} / \mathrm{kg}$; No: 20090222-09, Tianjin Chemical Reagent Co. Ltd., Tianjin, China), and bone marrow (4-6 mL) from their left and right iliac crests was collected and then added to canine lymphocyte separation fluid to isolate 
BMSCs (1:1, No: LTS1079, Tianjin TBD Co. Ltd., Tianjin, China). Dulbecco's Modified Eagle's Medium (DMEM) F12 culture fluid supplemented with 10\% fetal bovine serum and $100 \mathrm{IU} / \mathrm{mL}$ PS double antibody (No: SH30023.01B, HyClone, Logan, UT, USA) was then added. The samples were inoculated in culture bottles $\left(25 \mathrm{~cm}^{2}, 4 \mathrm{~mL}\right.$ per bottle) after mixing and cultured at $37^{\circ} \mathrm{C}$ under a constant temperature with $5 \% \mathrm{CO}_{2}$.

The cultured cells were examined using an inverted microscope to record cell growth and morphological features until the confluency reached $80-90 \%$. Third-generation BMSCs were obtained after centrifugation, resuspension and subculture using a room-temperature digestion method (RTDM) with trypsase (No: BR08211, Sigma-Aldrich, Inc., St. Louis, MO, USA). This process was repeated 3 times to obtain a cell suspension $\left(2 \times 10^{6} / \mathrm{mL}\right)$, which was then pressed through a 200 -mesh filter.

A total of $100 \mu \mathrm{L}$ of the cell suspension was added per flow cytometry test tube. Following this, FITC- or PE fluorescent-labeled monoclonal antibodies against the surface antigens CD34 (No: 12-0340, eBioscience, Inc., San Diego, CA, USA), CD45 (No: 12-5451, eBioscience, Inc., San Diego, CA, USA), CD90 (No: 12-5900, eBioscience, Inc., San Diego, CA, USA), and CD105 (No: 25-1057, eBioscience, Inc., San Diego, CA, USA) as well as isotype control antibodies ( $5 \mu \mathrm{L}$ per tube) were added, and the tubes were incubated for $15 \mathrm{~min}$ in the dark. The surface antigens were detected by flow cytometry; analysis was carried out with FCS Express 5 software (De Novo Software, Inc., Glendale, CA, USA).

\section{BMSC transfection}

The adenovirus vector plasmid Ad-BMP2-bFGF-GFP (containing the BMP-2 and bFGF genes) and the adenovirus vector Ad-GFP were purchased from Benyuan Zhengyang Gene Technology Co., Ltd. (Beijing, China). Second-generation BMSCs were inoculated in 12-well culture plates, digested and counted. The BMSCs were then transfected at a multiplicity of infection (MOI) of 50, 100, 200 or 400. According to the number of positive cells detected by fluorescence microscopy after $48 \mathrm{~h}$, the transfection efficiency was calculated to obtain the optimal MOI. The second-generation BMSCs were randomly divided into two groups, and Ad-BMP2-bFGF-GFP and Ad-GFP were then added to each group $(\mathrm{MOI}=100)$. A constant volume of $400 \mu \mathrm{L}$ of low-glucose Dulbecco's Modified Eagle's Medium (L-DMEM) was maintained. After cell transfection, the cells were maintained at a constant temperature of $37^{\circ} \mathrm{C}$ for $2 \mathrm{~h}$, after which $40 \mu \mathrm{L}$ fetal calf serum and $500 \mu \mathrm{L}$ complete medium were added into each well. The cells were then incubated at a constant temperature for $48 \mathrm{~h}$. Following this incubation, the medium was replaced, and the cells were observed and photographed under a fluorescence microscope. The medium was changed every 2 days, and the cells were passaged when the confluency reached $80-90 \%$.

\section{Western blotting}

Cells were collected $48 \mathrm{~h}$ after transfection with Ad-BMP2-bFGF-GFP, and IP cell lysis solution (No: P0013, Shanghai Beyotime Biotech Co. Ltd, Shanghai, China) was used to extract total cellular protein. The protein was visualized by Western blotting as follows. Sodium dodecyl sulfate-polyacrylamide gel electrophoresis (SDS-PAGE) was performed at a constant voltage on $50 \mu \mathrm{g}$ of denatured protein, and the electrophoresis products were transferred onto a polyvinylidene fluoride (PVDF) membrane using a semidry method. Then, the membrane was blocked with $5 \%$ skimmed milk powder for $2 \mathrm{~h}$ at $4^{\circ} \mathrm{C}$. A mouse BMP-2 monoclonal antibody (No: ab6285, Abcam Inc., Cambridge, MA, USA) and a mouse bFGF monoclonal antibody (No: ab10419, Abcam Inc., Cambridge, MA, USA) were incubated with the membrane as primary antibodies for $10 \mathrm{~h}$ at $4^{\circ} \mathrm{C}$, after which the membrane was washed 4 times with Tris-buffered saline plus Tween (TBST) for 10 min per wash. Goat anti-mouse IgG (No: ab6788, Abcam Inc., Cambridge, MA, USA) labeled with horseradish peroxidase was used as a secondary antibody. The membrane was incubated with the secondary antibody for $2 \mathrm{~h}$ at $37^{\circ} \mathrm{C}$ and again washed 4 times with TBST for 10 min per wash. An ECL kit was used as the chromogenic agent. The ratio of the gray level between target and reference proteins was used to indicate the relative amounts of BMP- 2 and bFGF, with $\beta$-actin being used as an internal control.

\section{Preparation of decalcified bone matrix (DBM)}

Periosteum was isolated from the fresh femurs of Beagle dogs (provided by the experimental animal center of our university). Slices $(2 \mathrm{~cm} \times 2 \mathrm{~cm} \times 5 \mathrm{~cm})$ from the metaphysis were frozen for 6 months at $-80^{\circ} \mathrm{C}$, then degreased for $8 \mathrm{~h}$ in $98 \%$ acetone and decalcified for $48 \mathrm{~h}$ in $0.6 \mathrm{~mol} / \mathrm{L}$ hydrochloric acid ( $\mathrm{HCl}$ ). A protein solution containing $2 \mathrm{~mol} / \mathrm{L}$ calcium chloride $\left(\mathrm{CaCl}_{2}\right), 0.5 \mathrm{~mol} / \mathrm{L}$ ethylene diamine tetraacetic acid (EDTA), and $8 \mathrm{~mol} / \mathrm{L} \mathrm{LiCl}$ was formulated (1:1:1) and then incubated with the degreased bone and 


\section{Cellular Physiology Cell Physiol Biochem 2017;43:1648-1662 \begin{tabular}{l|l|l} 
and Biochemistry Published onlIne: October 18, 2017 & $\begin{array}{l}\text { (c) } 2017 \text { The Author(s). Published by S. Karger AG, Basel } \\
\text { www.karger.com/cpb }\end{array}$ \\
\hline
\end{tabular}}

Peng et al.: Bmscs Combined with DBM to Repair ONFH

decalcified bone for $4 \mathrm{~h}$ at $4^{\circ} \mathrm{C}$. The bones were then washed 3 times with distilled water before undergoing lyophilization for $8 \mathrm{~h}$. Following this, they were packed into bilayer polyethylene films and stored at $4^{\circ} \mathrm{C}$ for later use after disinfection with ethylene oxide for $48 \mathrm{~h}$.

Construction of the DBM/BMSC complex and evaluation of the cell adhesion rate

Eight slices ( $3 \mathrm{~mm} \times 3 \mathrm{~mm} \times 3 \mathrm{~mm}$ ) were made from DBM, disinfected with ethylene oxide for $48 \mathrm{~h}$ and placed into 6-well culture plates with 2 slices per well. The slices were soaked in DMEM for $48 \mathrm{~h}$; the medium was changed 3 times to maintain the $\mathrm{pH}$ (7.2-7.3). Sterile gauze was used to absorb water after the slices were soaked in DMEM supplemented with 20\% fetal calf serum for $12 \mathrm{~h}$.

Osteoblastic differentiation was induced by incubating third-generation transfected BMSCs in highglucose DMEM (Becton, Dickinson and Company, Franklin Lakes, NJ, USA) containing $100 \mathrm{U} / \mathrm{mL}$ penicillin, $100 \mu \mathrm{g} / \mathrm{mL}$ streptomycin, $50 \mathrm{ng} / \mathrm{mL}$ dexamethasone, $10 \mathrm{mmol} / \mathrm{L} \beta$-glycerol phosphate and $50 \mu \mathrm{g} / \mathrm{mL}$ ascorbic acid. Following this, the cells were submitted to further culture. The medium was replaced every 2 days, and the cells were passaged when the confluency reached 80-90\%.

A $0.25 \%$ trypsin solution was used to digest and collect second-generation canine BMSCs on day 7 of culture in osteogenic induction medium, and the cells were adjusted to a concentration of $2 \times 10^{9}$ cells/ $\mathrm{mL}$. The DBM was deformed by sterile forceps, and the cell suspension was overlaid on the matrix as it was restored from the compression, creating negative pressure. In this way, the cells were aspirated into the bottom of the DBM stent until the DBM was completely soaked by the cell suspension. Then, $2 \mathrm{~mL}$ of the cell suspension was added to each DBM sample, and the samples were cultured at $37^{\circ} \mathrm{C}$ under $5 \% \mathrm{CO}_{2}$ and at saturated humidity for $5 \mathrm{~h}$. Osteogenic induction medium supplemented with $10 \%$ fetal bovine serum was then added to the culture plate, and the numbers and adhesion rates for the DBM/BMSCs were calculated after 5, 12 and $24 \mathrm{~h}$ as follows: number of adhered cells = number of inoculated cells - number of nonadherent cells; adhesion rate $=($ number of adhered cells $/$ number of inoculated cells $) \times 100 \%$.

\section{Establishment of canine model of ONFH}

Thirty Beagle dogs were weighed and intravenously injected with $3 \%$ pentobarbital sodium (1 mL/ kg, 20090222-09, Tianjin Chemical Reagent Co. Ltd., Tianjin, China). After successful anesthesia, an incision was made on the lateral side of the right hip joint to expose the hip joint capsule from the posterior to the anteromedial side and the joint capsules and ligaments were then cut. A 4-mm-diameter drill bit was used to drill holes in the weight-bearing area of the right femoral head, and a full-thickness defect model was made in the area of the bilateral femoral heads. The thickness of the defect model was equal to that of the cartilage in the weight-bearing area of the femoral head in Beagle dogs. The procedures used to establish the left femoral head model were the same as those used for the right femoral head model. A model of ONFH (containing both the left and right femoral heads) was successfully established in all thirty animals.

\section{Experimental grouping and material implantation}

Thirty Beagle dogs were randomized equally into five groups: control, DBM, DBM/BMSC, Ad-BMP2bFGF-GFP and Ad-GFP (each with an $n=6$ ). After being washed with normal saline, the excess tissues in the bone defect areas were removed. The defect areas were filled until the height of the area was equal to the surrounding cartilage tissue, and then the joint capsules and tissues were sutured. In the control group, the excess tissues in the bone defect areas were washed with normal saline, but the defect areas were not filled. DBM was used to fill the defect area in the DBM group, the BMSC-DBM composite was used to fill the defect area in the DBM/BMSC group, BMSCs transfected with Ad-BMP2-bFGF-GFP and combined with DBM were used to fill the defect area in the Ad-BMP2-bFGF-GFP group, and BMSCs transfected with Ad-GFP and combined with DBM were used to fill the defect area in the Ad-GFP group. All the implanted BMSCs were derived from autologous BMSCs. After surgery, all animals underwent X-ray examination to check on the filling (Fig. 1). Injections of penicillin $\left(8 \times 10^{5} \mathrm{U}\right)$ were performed 3 days after the operation. The dogs were allowed to move freely after the operation.

\section{Hematoxylin and eosin (HE) and Masson's trichrome staining}

Two dogs per group were sacrificed at 3,6, and 12 weeks after the operation. The samples of repaired femoral head cartilage were fixed with $4 \%$ formaldehyde, embedded in paraffin and sliced at a $5-\mu \mathrm{m}$ thickness. The slices were observed under a light microscope and further examined using HE and Masson's trichrome staining. 


\section{Cellular Physiology Cell Physiol Biochem 2017;43:1648-1662

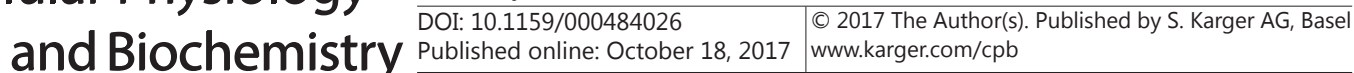 \\ Peng et al.: Bmscs Combined with DBM to Repair ONFH}

Fig. 1. Skiagrams of the bone defect area in a dog after the operation (A) and after filling the area with demineralized bone matrix (B)

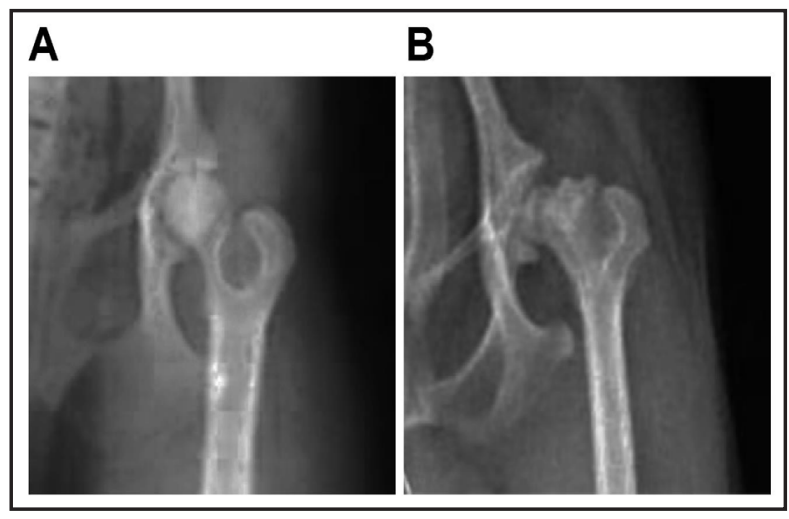

\section{$X$-ray detection and evaluation}

X-ray examinations were performed $(60 \mathrm{kV}, 50 \mathrm{~mA}$ and $0.12 \mathrm{~s})$ at 3, 6, and 12 weeks after the operation. The formation of new bone in the modeling area was scored using Image-Pro Plus 6.0 (Media Cybernetics, Washington, MD, USA) as follows: new bone of normal bone mineral density filling less than $25 \%$ of the defect area, 1 point; new bone of normal bone mineral density filling 25-50\% of the defect area, 2 points; new bone of normal bone mineral density filling 50-75\% of the defect area, 3 points; and new bone of normal bone mineral density filling $75-100 \%$ of the defect area, 4 points.

\section{Measurement of new bone areas}

HE staining was used to visualize the samples of repaired femoral head cartilage at 3, 6, and 12 weeks after the operation. The samples were fixed with $40 \mathrm{~g} / \mathrm{L}$ paraformaldehyde for $24 \mathrm{~h}$ and dehydrated in increasing grades of $10 \%$ ethylene diamine tetraacetic acid (EDTA) decalcifying fluid. The tissues were dissected, embedded in paraffin, and sectioned to a 5- $\mu$ m thickness. The sections were then stained for $5 \mathrm{~min}$ in $0.5 \%$ hematoxylin solution and immersed in distilled water for a short time. After washing with water, the samples were bleached for $1 \mathrm{~h}$ and rinsed with water. After undergoing dehydration through a gradient of $70 \%$ and $90 \%$ ethanol, the sections were stained in eosin solution for 3 min and then sealed with neutral gum. Cells were visualized under a microscope and then photographed. Four femoral heads per group were selected, and 3 sections of each femoral were extracted randomly and observed under a $4 \times$ 100 visual field. To observe areas of new bone formation, four fields were selected from each section: two were used to observe the edge of the femoral heard and two to observe necrotic zones. The new bone that had formed contained a high proportion of scattered trabecular bone with clear margins, and numerous bone cells or osteoblasts surrounded by connective tissues could be seen in the trabecular bone. The images were analyzed to calculate the percentage of new bone area using an image analysis system (model HPIAS-1000, Imaging Company of Tongji Medical University, Shanghai, China) as follows: percentage of new bone formation area $=$ new bone area $/$ entire visual field $\times 100 \%$.

\section{Immunohistochemistry}

Immunohistochemical staining to detect a CD34 monoclonal antibody (No: 12-0340, eBioscience, San Diego, CA, USA) was applied to the slices of the femoral head from each group at 3, 6, and 12 weeks after the operation. $\mathrm{ABC}$ immunohistochemical staining was performed. Positive staining located in the cytoplasms of vascular endothelial cells appeared yellow brown, and previously identified positive histological slices were chosen as positive controls. Four femoral heads were selected per group, and 3 sections of each femoral head were randomly extracted. The samples were observed under a $4 \times 100$ visual field. Four fields were selected from each section: two were used to observe the edge of the femoral head and two to observe necrotic zones. An HPIAS-1000 high-definition color pathological graphics context report system was used to measure the area containing new blood vessels and to count the density of the new blood vessels as follows: density of new blood vessels $=$ the area of new blood vessels / total area $\times 100 \%$.

Evaluation of compressive strength and bending strength

Healthy femoral heads were selected as controls 12 weeks after the operation. Four femoral heads from each group were flushed with normal saline, and the compressive strength and bending strength of 


\section{Cellular Physiology Cell Physiol Biochem 2017;43:1648-1662

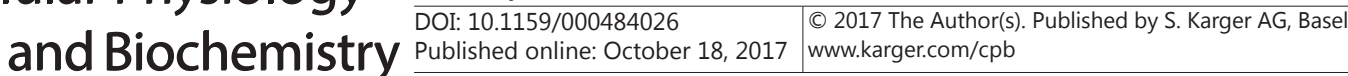 \\ Peng et al.: Bmscs Combined with DBM to Repair ONFH}

the bones were examined using a universal material testing machine (No: 3360, Instron Inc., USA) until fractures appeared. The measurements were then statistically analyzed.

\section{Statistical analysis}

SPSS 19.0 (SPSS, Inc., Chicago, IL, USA) was used to analyze all data. Measurement data were expressed as the mean \pm standard deviation (mean \pm SD). Variance analysis was used to compare differences between multiple groups. The Student-Newman-Keuls (SNK) method was used for comparisons between two groups. Variables with a non-normal distribution were expressed as the median and interquartile range. The rank sum test was applied for intergroup comparisons. $P<0.05$ indicated a statistically significant difference.

\section{Results}

Morphology and identification of canine BMSCs in each group

Primary cells were observed under an inverted microscope after $48 \mathrm{~h}$ of culture and a medium change (Fig. 2-A). Sporadic adherent cells were scattered between suspended cells, which had a short-fusiform, triangle or polygon shape with strong light refraction from the cytoplasm. After 7 days of culture, the primary cells had spread across the bottom of the culture plate (Fig. 2-B). As the cell density increased, the cells merged into a long-fusiform

Fig. 2. Morphology of primary BMSCs from Beagle dogs detected by light microscopy and flow cytometry Note: A, primary culture of BMSCs for $48 \mathrm{~h}(\mathrm{x}$ 100); B, seven-day primary culture of BMSCs $(\times 100)$; C, expression of CD45, CD34, CD90 and CD105 on the surface of third-generation BMSCs from Beagle dogs; BMSCs, bone marrow mesenchymal stem cells.
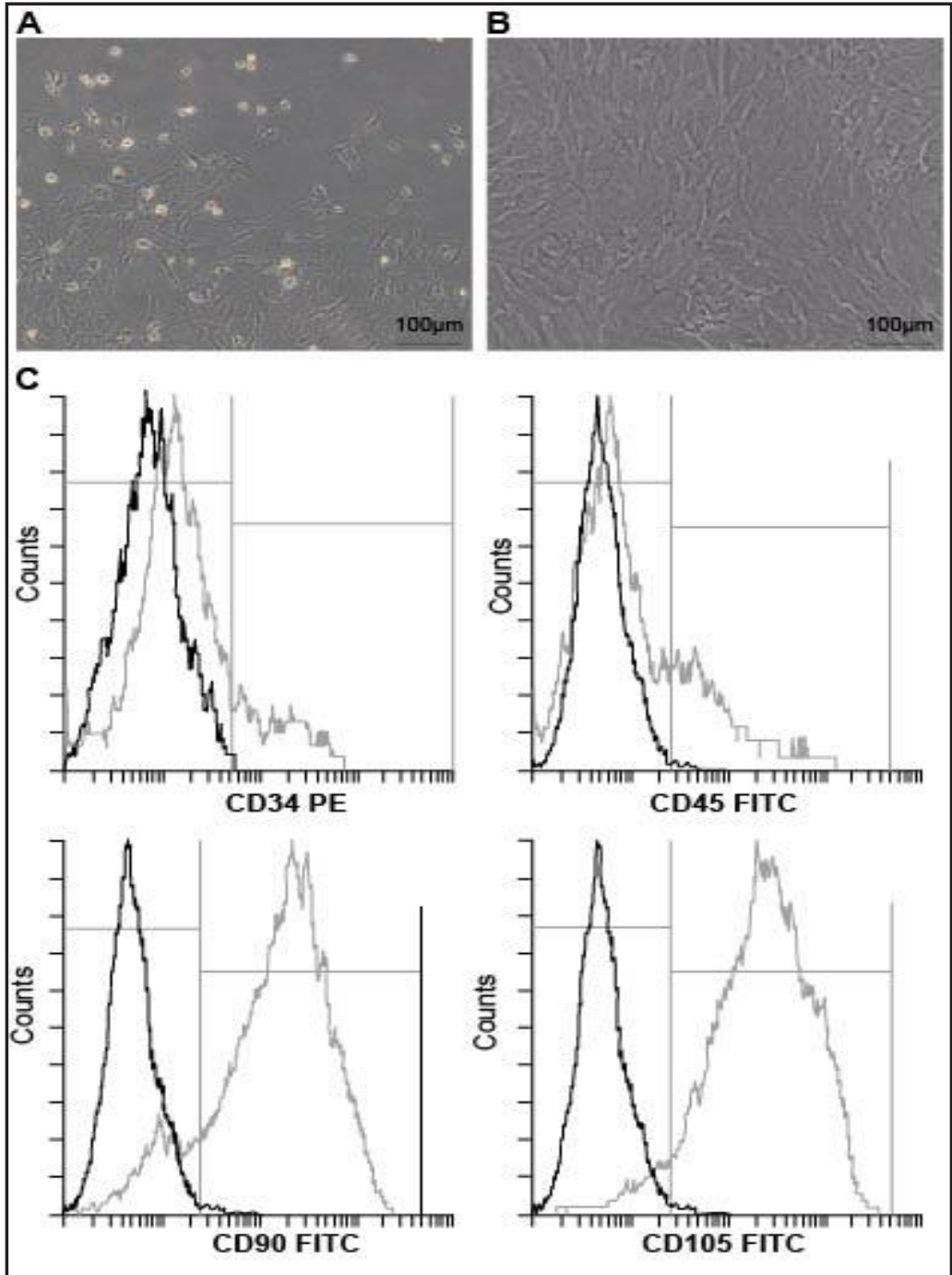
shape and grew in aggregates. The expression of surface markers on third-generation BMSCs was investigated by flow cytometry (Fig. 2-C). The percentages of cells expressing CD45, CD34, CD90 and CD105 were 0.04\%, 3.82\%, 96.43\% and 93.17\%, respectively, indicating that BMSCs had been successfully isolated and cultured.

\section{Determining the optimal MOI for adenoviral infection of BMSCs}

Obvious GFP expression could be observed two weeks after adenovirus infection, indicating that the virus was successfully delivered into the cells. The results of fluorescence staining when virus was delivered at an MOI of 100 are shown in Fig. 3-A. The viral infection rates for different viral titers are shown in Fig. 3-B. The infection efficiency exceeded $80 \%$ at an MOI of 100 and was significantly higher than that obtained at an MOI of 50, 200, or 400 (all $P<0.05$ ).

\section{BMP-2 and bFGF protein expression in BMSCs detected by Western blotting}

Western blotting results are shown in Fig. 4 . At $48 \mathrm{~h}$ after transfection, the expression of BMP-2 and bFGF in the Ad-BMP2-bFGF-GFP group was significantly higher than in the AdGFP group and the normal group (all $P<0.05$ ).

Fig. 3. Optimizing the multiplicity of infection (MOI) for adenovirus in canine bone marrow mesenchymal stem cells (BMSCs)Note: A, expression of green fluorescent protein at an MOI of 100; arrows represent positive
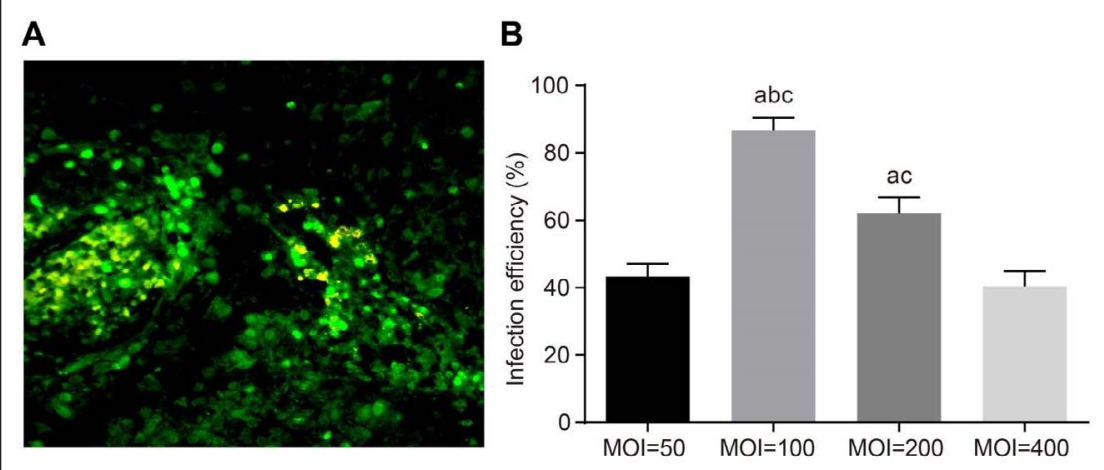
expression of green

fluorescent protein; B, infection efficiency of BMSCs at multiple MOIs; ${ }^{a}$ refers to $\mathrm{P}<0.05$ compared with the MOI = 50 group; ${ }^{\mathrm{b}}$ refers to $\mathrm{P}<0.05$ compared with the MOI $=400$ group; MOI, multiplicity of infection.

Fig. 4. Expression of BMP-2 and bFGF protein in each groupNote: A, BMP-2 and bFGF expression in the BMSCs from each group; B, statistical analysis of gray levels from panel A; * refers to $\mathrm{P}<0.05$ compared with the Ad-GFP group; \# refers to $\mathrm{P}<0.05$ compared with the normal group; BMSCs, bone marrow

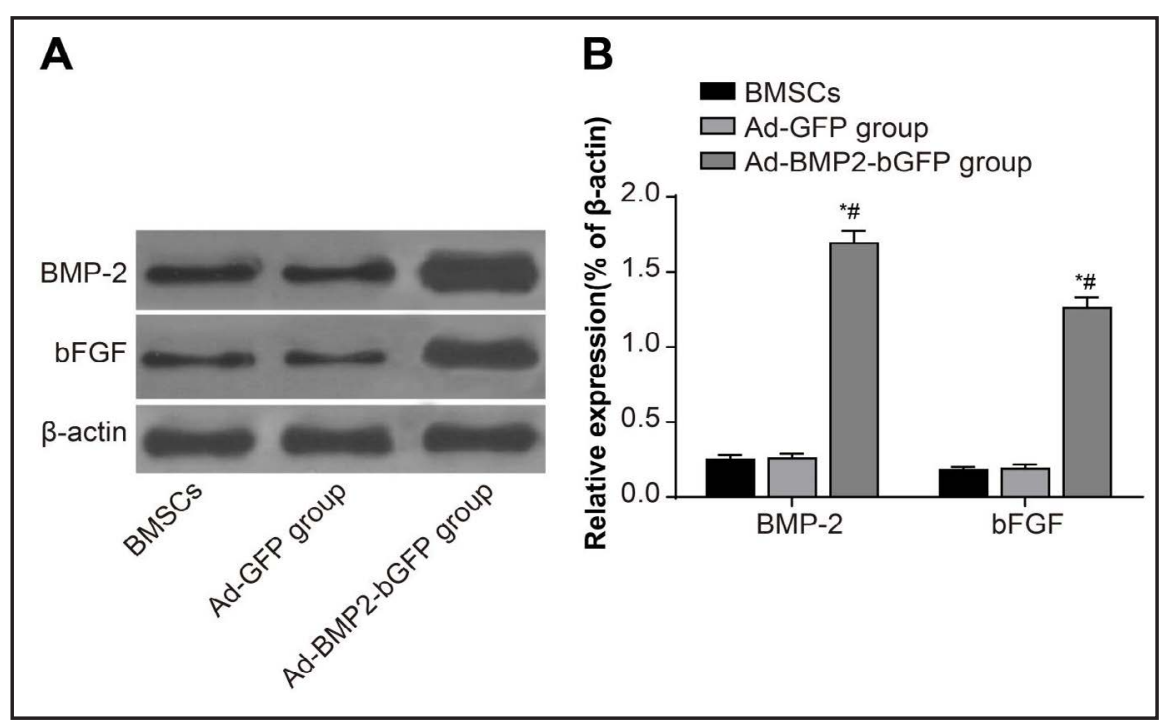

mesenchymal stem cells; DBM, demineralized bone matrix; BMP-2, bone morphogenetic protein 2; bFGF, basic fibroblast growth factor; Ad-GFP; adenovirus control plasmid encoding green fluorescent protein. 
Fig. 5. Cell adhesion rates of BMSCs at different time pointsNote: * refers to $\mathrm{P}<0.05$ compared with the 5-h group; BMSCs, bone marrow mesenchymal stem cells.
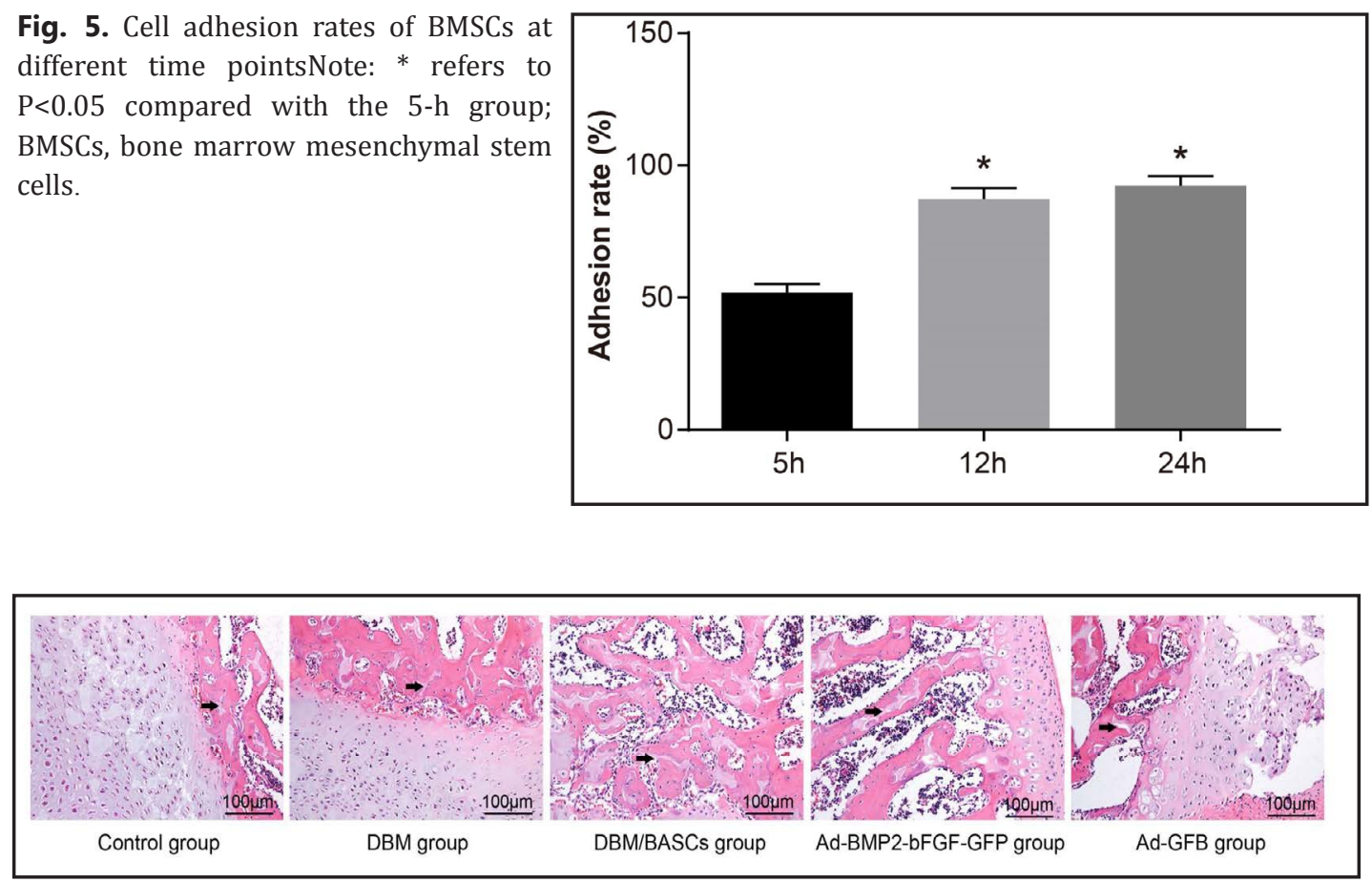

Fig. 6. Bone morphology and HE staining results in all five groups at 12 weeks after the operation Note: the bone morphology in each group at 12 weeks after the operation (HE staining, $\times 100$ ); the arrow refers to the trabecular bone; BMSCs, bone marrow mesenchymal stem cells; HE, hematoxylin-eosin; DBM, demineralized bone matrix; BMP-2, bone morphogenetic protein 2; bFGF, basic fibroblast growth factor; Ad-GFP; adenovirus control plasmid encoding green fluorescent protein.

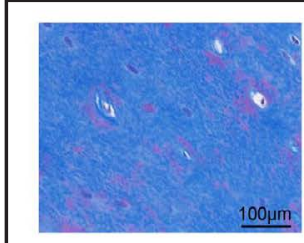

Control group

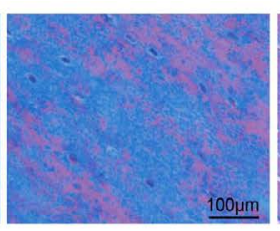

DBM group

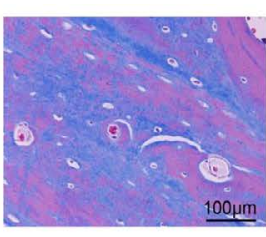

DBM/BASCs group

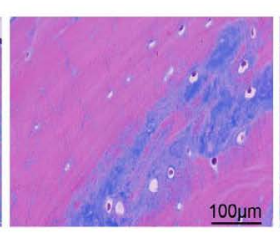

Ad-BMP2-bFGF-GFP group

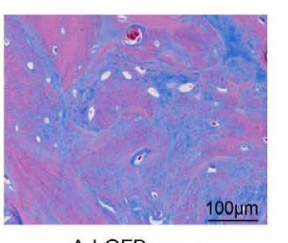

Ad-GFB group

Fig. 7. Bone morphology in the repaired samples of femoral head cartilage from all five groups at 12 weeks after the operation visualized using Masson's Trichrome staining ( $\times 100)$ Note: BMSCs, bone marrow mesenchymal stem cells; HE, hematoxylin-eosin; DBM, demineralized bone matrix; BMP-2, bone morphogenetic protein 2; bFGF, basic fibroblast growth factor; Ad-GFP; adenovirus control plasmid encoding green fluorescent protein.

\section{BMSC adhesion rates for each group}

The rates of adhesion for the BMSCs overlaid onto DBM at different times are displayed in Fig. 5. The adhesion rate was approximately $51.97 \%$ after $5 \mathrm{~h}$, which increased to approximately $87.26 \%$ after $12 \mathrm{~h}$ and then to $92.31 \%$ after $24 \mathrm{~h}(P<0.05)$.

\section{Observation of BMSCs using HE staining}

No infection or death was observed in the animals during the experiments. The results of HE and Masson's trichrome staining are shown in Fig. 6 and Fig. 7, respectively. In boneimplant zones that were filled with collagen, extensive necrosis was found in trabecular bone, which spread to the medullary cavity. Many osteoclasts were present, and empty 
Fig. 8. Skiagrams of the femoral heads of dog bones at 6 and 12 weeks after the operation in the control (a-b), DBM (c-d), DBM/ BMSC (e-f), Ad-BMP2-bFGF-GFP (g-h) and Ad-GFP (i-j) groupsNote: DBM, demineralized bone matrix; BMP-2, bone morphogenetic protein 2; bFGF, basic fibroblast growth factor; Ad-GFP; adenovirus control plasmid encoding green fluorescent protein.

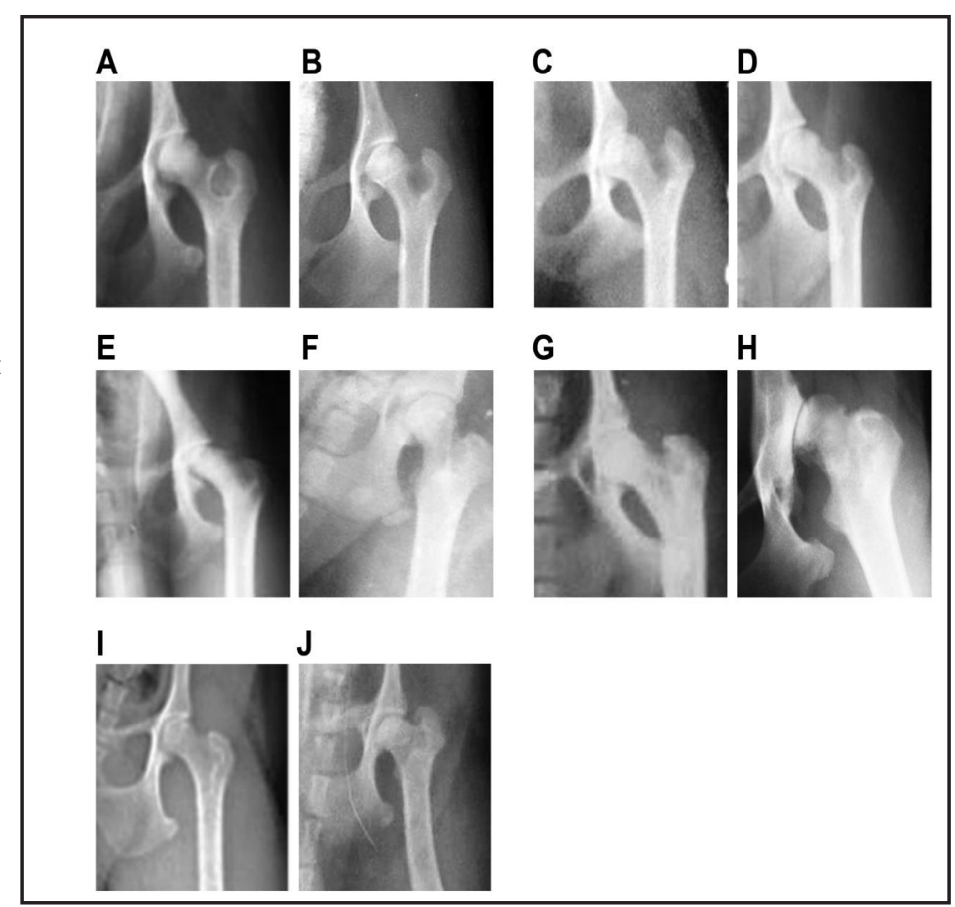

lacuna could be observed in the control group at 12 weeks after surgery. The defect area included a substantial amount of collagen, indicating an osteogenic response, and there was little immature trabecular bone, which had an irregular structure, in the DBM group after 12 weeks. Although the DBM/BMSC group showed a significantly higher proportion of new trabecular bone by 12 weeks after the operation compared with the DBM group, most of the trabecular bone was immature, and necrotic bone tissue was present. Less necrotic bone was present in the DBM/BMSC group than the DBM group. There was also less collagenous tissue in the DBM/BMSC group than the DBM group. The filled area was covered by immature trabecular bone, with numerous clear bone cells on the surface. The proportion of collagenous tissue was further reduced in the Ad-BMP2-bFGF-GFP group at 12 weeks after the operation. The changes in the Ad-GFP group were consistent with those in the DBM/BMSC group.

\section{Scoring new bone formation using X-ray}

The results of X-ray examination showed that the defect areas in the control group could be clearly visualized 6 and 12 weeks after the operation. In the DBM group, no new bone formation was observed in the $6^{\text {th }}$ week, and only a small amount of new bone with a decreased density in the bone-implant zone was observed in the $12^{\text {th }}$ week after the operation. In the DBM/BMSC group, there was a small amount of new bone but no continuous trabecular bone by 6 weeks after the operation, and some trabecular bone but with uneven density in the bone-implant zone was observed in the $12^{\text {th }}$ week. In the Ad-BMP2-bFGF-GFP group, there was formation of new bone tissue but at a low density at 6 weeks after the operation; by 12 weeks, there was a substantial amount of new bone tissue with nearly normal density in the bone-implant zone. In the Ad-GFP group, there was some new bone tissue but no continuous trabecular bone at 6 weeks after the operation, but a substantial amount of new bone had formed but with uneven density in the bone-implant zone by 12 weeks. The AdGFP group had similar characteristics to the DBM/BMSC group (Fig. 8).

The X-ray score for each group is shown in Table 1. The Ad-BMP2-bFGF-GFP group had significantly higher scores than the control, DBM, DBM/BMSC and Ad-GFP groups at all time points (all $P<0.05$ ). The DBM, DBM/BMSC, Ad-BMP2-bFGF-GFP and Ad-GFP groups also had significantly higher scores than the control group at all time points (all $P<0.05$ ). The DBM/ 
Table 1. Scoring of new bone formation detected by X-ray among the different groups (mean \pm SD). Note: a, refers to $P<0.05$ compared with the control group at the same time; ${ }^{\text {b }}$, refers to $P<0.05$ compared with the DBM group at the same time; ${ }^{c}$, refers to $P<0.05$ compared with the DBM/BMSC group or the Ad-GFP group at the same time; ${ }^{\mathrm{d}}$, refers to $P<0.05$ compared with the same group in the $3^{\text {rd }}$ week; SD, standard deviation; BMSCs, bone marrow mesenchymal stem cells; DBM, demineralized bone matrix; BMP-2, bone morphogenetic protein 2; bFGF, basic fibroblast growth factor; AdGFP; adenovirus control plasmid encoding green fluorescent protein.

\begin{tabular}{lccc}
\hline Group & $\begin{array}{c}\text { Third week } \\
(\mathrm{n}=12)\end{array}$ & $\begin{array}{c}\text { Sixth week } \\
(\mathrm{n}=8)\end{array}$ & $\begin{array}{c}\text { Twelfth week } \\
(\mathrm{n}=4)\end{array}$ \\
\hline Control group & $0.72 \pm 0.56$ & $0.95 \pm 0.68$ & $0.97 \pm 0.54$ \\
DBM group & $1.23 \pm 0.29^{\mathrm{a}}$ & $2.34 \pm 0.37^{\mathrm{ad}}$ & $1.87 \pm 0.52^{\mathrm{ad}}$ \\
DBM/BMSC group & $1.85 \pm 0.49^{\mathrm{ab}}$ & $2.97 \pm 0.35^{\mathrm{abd}}$ & $2.89 \pm 0.52^{\mathrm{abd}}$ \\
Ad-BMP2-bFGF-GFP group & $2.82 \pm 0.45^{\mathrm{abc}}$ & $3.74 \pm 0.45^{\mathrm{abcd}}$ & $3.86 \pm 0.41^{\mathrm{abcd}}$ \\
Ad-GFP group & $1.76 \pm 0.48^{\mathrm{ab}}$ & $2.96 \pm 0.36^{\mathrm{abd}}$ & $2.89 \pm 0.60^{\mathrm{abd}}$ \\
\hline
\end{tabular}

Table 2. Relative quantitative analysis of the new bone area formed at different time points among the 5 tested groups (mean $\pm \mathrm{SD}, \mathrm{n}=48$ ). Note: ${ }^{\text {a }}$, refers to $P<0.05$ compared with the control group at the same time; b, refers to $P<0.05$ compared with the DBM group at the same time; ${ }^{\mathrm{c}}$, refers to $P<0.05$ compared with the DBM/BMSC group or the Ad-GFP group at the same time; ${ }^{d}$, refers to $P<0.05$ compared with the same group in the 3rd week. BMSCs, SD, standard deviation; bone marrow mesenchymal stem cells; DBM, demineralized bone matrix; BMP-2, bone morphogenetic protein 2; bFGF, basic fibroblast growth factor; Ad-GFP; adenovirus control plasmid encoding green fluorescent protein.

\begin{tabular}{lccc} 
Group & Third week & Sixth week & Twelfth week \\
\hline Control group & $1.78 \pm 0.12$ & $2.25 \pm 0.21$ & $2.46 \pm 0.22$ \\
DBM group & $2.78 \pm 0.41^{\mathrm{a}}$ & $5.01 \pm 0.62^{\mathrm{ad}}$ & $8.57 \pm 0.53^{\mathrm{ad}}$ \\
DBM/BMSC group & $3.86 \pm 0.52^{\mathrm{ab}}$ & $9.81 \pm 0.65^{\mathrm{abd}}$ & $32.62 \pm 0.44^{\mathrm{abd}}$ \\
Ad-BMP2-bFGF-GFP group & $25.89 \pm 0.47^{\mathrm{abc}}$ & $32.82 \pm 0.51^{\mathrm{abcd}}$ & $41.36 \pm 0.67^{\mathrm{abcd}}$ \\
Ad-GFP group & $3.91 \pm 0.48^{\mathrm{ab}}$ & $9.53 \pm 0.64^{\mathrm{abd}}$ & $32.91 \pm 0.48^{\mathrm{abd}}$ \\
\hline
\end{tabular}

Table 3. New blood vessel density at different time points among the 5 tested groups ( $m e a n \pm S D, n=48$ ) Note: ${ }^{a}$, refers to $P<0.05$ compared with the control group at the same time; ${ }^{\text {b }}$, refers to $P<0.05$ compared with the DBM group at the same time; ${ }^{c}$, refers to $P<0.05$ compared with the DBM/BMSC group or the Ad-GFP group at the same time; ${ }^{d}$, refers to $P<0.05$ compared with the same group in the 3rd week; SD, standard deviation; BMSCs, bone marrow mesenchymal stem cells; DBM, demineralized bone matrix; BMP-2, bone morphogenetic protein 2; bFGF, basic fibroblast growth factor; Ad-GFP; adenovirus control plasmid encoding green fluorescent protein.

\begin{tabular}{lccc}
\hline Group & Third week & Sixth week & Twelfth week \\
\hline Control group & $3.34 \pm 0.51$ & $4.74 \pm 1.01$ & $7.65 \pm 1.03$ \\
DBM group & $6.72 \pm 0.52^{\mathrm{a}}$ & $6.50 \pm 1.09^{\mathrm{ad}}$ & $9.58 \pm 1.51^{\mathrm{ad}}$ \\
DBM/BMSC group & $7.91 \pm 0.31^{\mathrm{ab}}$ & $10.12 \pm 1.63^{\mathrm{abd}}$ & $16.65 \pm 2.44^{\mathrm{abd}}$ \\
Ad-BMP2-bFGF-GFP group & $18.27 \pm 1.90^{\mathrm{abc}}$ & $20.97 \pm 2.84^{\mathrm{abcd}}$ & $25.75 \pm 3.67^{\mathrm{abcd}}$ \\
Ad-GFP group & $8.43 \pm 2.12^{\mathrm{ab}}$ & $14.35 \pm 1.33^{\mathrm{abd}}$ & $17.30 \pm 1.45^{\mathrm{abd}}$ \\
\hline
\end{tabular}

BMSC, Ad-BMP2-bFGF-GFP and Ad-GFP groups had significantly higher scores than the DBM group at all time points (all $P<0.05$ ). The DBM, DBM/BMSC, Ad-BMP2-bFGF-GFP and AdGFP groups had significantly higher scores at 6 and 12 weeks after the operation compared to 3 weeks after the operation (all $P<0.05$ ).

Assessments of new vessel density and new bone area in each group

The results from the quantitative analysis of new bone area are shown in Table 2 and Fig. 9A. The measurements of new blood vessel density are shown in Table 3 and Fig. 9B. HE staining during the $6^{\text {th }}$ week after the operation showed that the control group defect area was filled with connective tissue and little new bone. Incomplete absorption of filler appeared in the DBM and DBM/BMSC groups. By contrast, the filler was completely absorbed and formed many new regions of trabecular bone with high blood vessel density in the AdBMP2-bFGF-GFP group, and there was a substantial area of new bone tissue in the Ad-GFP group. Immunohistochemical staining showed a low density of new blood vessels and little increase in this density over time in the control and DBM groups. Compared with the control and DBM groups, there was a higher density of new blood vessels and an increase in this density over time in the DBM/BMSC and Ad-GFP groups. The Ad-BMP2-bFGF-GFP group had the highest density of new blood vessels, indicating that this group experienced the greatest degree of repair. Quantitative analysis using image analysis software revealed significantly KARGER 


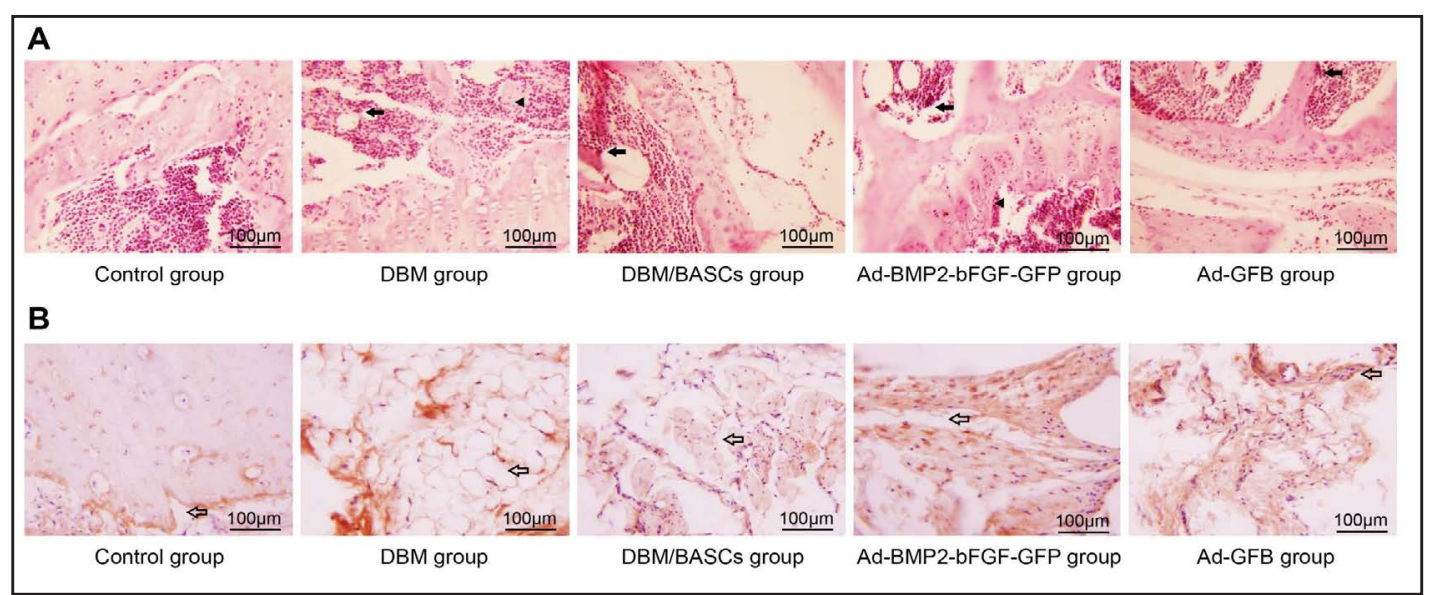

Fig. 9. Formation of new bone and blood vessels at 6 weeks after the operation in each group visualized using HE staining and immunohistochemistryNote: A, formation of new bone in each group; the observed area in the control group was filled with connective tissue and was loosely associated with the main bone tissue; the DBM group showed little new bone tissue and incomplete absorption of filler (shown by arrows); the DBM/BMSC group showed little new bone tissue but greater absorption of filler than the DBM group (shown by arrows), indicating a greater degree of repair; the Ad-BMP2-bFGF-GFP group showed complete absorption of filler and a high degree of trabecular bone formation and blood vessel formation (shown by arrows); the Ad-GFP group showed a high degree of new bone tissue formation (shown by arrows). B, formation of new blood vessels in each group; the control and DBM groups had a low density of new blood vessels; the DBM/BMSC and Ad-GFP groups had a higher density of new blood vessels than the control and DBM groups; the Ad-BMP2-bFGF-GFP group had the highest density of new blood vessels, indicating that this group experienced the greatest degree of repair. The hollow arrows represent new blood vessels.

Fig. 10. Comparison of the compressive strength and bending strength of BMSCs among the tested groups Note: normal was considered normal canine bone; A, the compressive strength of each group; B: the bending strength of each group; a refers to $\mathrm{P}<0.05$ compared with the normal group; b refers to $\mathrm{P}<0.05$ compared with the DBM group; ${ }^{\mathrm{c}}$ refers to $\mathrm{P}<0.05$ compared with the DBM/BMSC group or the Ad-GFP group; BMSCs, bone

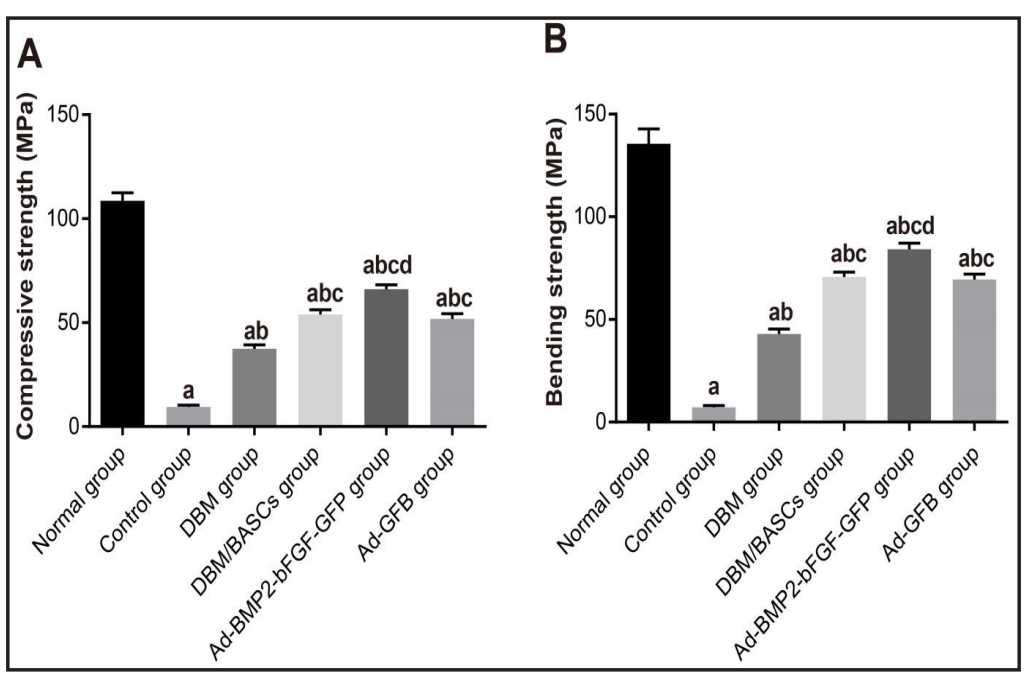
marrow mesenchymal stem cells; DBM, demineralized bone matrix; BMP-2, bone morphogenetic protein 2; bFGF, basic fibroblast growth factor; Ad-GFP; adenovirus control plasmid encoding green fluorescent protein.

greater blood vessel density and a larger area of new bone formation in the Ad-BMP2-bFGFGFP group compared with the control, DBM, DBM/BMSC and Ad-GFP groups at all time points (all $P<0.05$ ). The DBM, DBM/BMSC, Ad-BMP2-bFGF-GFP and Ad-GFP groups had significantly greater blood vessel density and a larger area of new bone formation compared with the control group at all time points (all $P<0.05$ ). The DBM/BMSC, Ad-BMP2-bFGF-GFP 


\section{Cellular Physiology Cell Physiol Biochem 2017;43:1648-1662

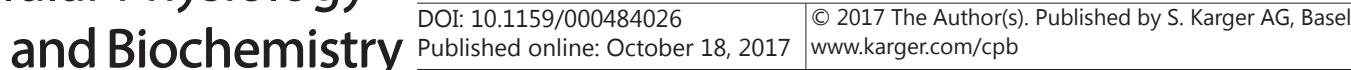

Peng et al.: Bmscs Combined with DBM to Repair ONFH

and Ad-GFP groups had significantly higher blood vessel density and a larger area of new bone formation than the DBM group at all time points (all $P<0.05$ ). The DBM, DBM/BMSC, Ad-BMP2-bFGF-GFP and Ad-GFP groups all showed a larger area of new bone and a higher blood vessel density at 6 and 12 weeks after the operation compared to at 3 weeks (all $P<$ 0.05).

Compressive strength and bending strength among different groups

Each group's results from the compressive strength testing at 12 weeks after surgery are shown in Fig. 10-A, and a comparison of bending strength is shown in Fig. 10-B. The AdBMP2-bFGF-GFP group had significantly greater compressive strength and bending strength than the control, DBM, DBM/BMSC and Ad-GFP groups (all $P<0.05$ ). The DBM, DBM/BMSC, Ad-BMP2-bFGF-GFP and Ad-GFP groups had significantly greater compressive strength and bending strength than the control group (all $P<0.05$ ). The DBM/BMSC, Ad-BMP2-bFGF-GFP and Ad-GFP groups had significantly greater compressive strength and bending strength than the DBM group (all $P<0.05$ ).

\section{Discussion}

In this study, we investigated the reparative effect of Ad-BMP-2/bFGF-modified BMSCs combined with DBM on ONFH in 30 Beagle dogs. ONFH models were successfully established in all specimens. We demonstrated that the protein expression of BMP-2 and bFGF was higher in the BMSCs transfected with the adenovirus vector plasmid Ad-BMP2-bFGF-GFP. The combination of these modified BMSCs with DBM (Ad-BMP2-bFGF-GFP group) was the more effective treatment for ONFH compare with the other four groups showing a larger area of new bone, higher X-ray scores, greater neovascularization density, and increased compressive and bending strength.

Initially, we found that necrosis of the trabecular bone and medullary cavity and the compression of empty lacuna were visible in the control group at 12 weeks after surgery. The major pathological change associated with ONFH is the obstruction of blood supply, which interrupts the microcirculation in the femoral head [21]. As a result, necessary nutrients may not be delivered to the bone tissues, causing the death of osteocytes, bone marrow edema and ultimately the destruction of bone structure [22]. In the $12^{\text {th }}$ week after the operation, the DBM group showed osteogenesis in the vicinity of the defect area, which gradually expanded to the central part of the femoral head. Allograft tissue was used to create the DBM, which also contained BMPs, collagen, and synergistic proteins including transforming growth factor and insulin-like growth factor. The presence of this milieu suggests that the DBM had both osteoinductive and osteoconductive ability, which led to excellent bony fusion $[23,24]$. Compared to recombinant growth factors, DBM is less expensive and is not limited in quantity. However, there are some disadvantages with using DBM, including its inherently variable osteoinductive potential [25]. Variability is present among different donors and carriers and also results from the demineralization and sterilization methods used, which may lead to unpredictable treatment results. Furthermore, the type of DBM used can affect the final treatment outcome [26]. Another potential concern stems from animal studies indicating that the use of DBM can be nephrotoxic [27]. In the present study, the DBM/BMSC group showed an increase in trabecular bone and a significant decrease in necrotic tissue by 12 weeks after the operation. DBM has a fibrous and porous structure, which should theoretically allow both cell adhesion and growth. This structure also plays a role in the penetration of nutrients into the matrix, which accelerates cell proliferation [28]. DBM also contains a large amount of BMP and has shown osteoinductive potential in vivo [29]. BMSCs are a promising seed-cell source for bone repair, which can be achieved using micro-fracture surgery [30]. Thus, combining BMSCs with DBM should have a synergistic effect on the treatment of bone defects. Moreover, when DBM, a resorbable biomaterial, is seeded with BMSCs, it can promote the adhesion and proliferation of MSCs [31]. In the present study, when the bone defect areas in the Ad-BMP2-bFGF-GFP group were filled with 


\section{Cellular Physiology Cell Physiol Biochem 2017;43:1648-1662

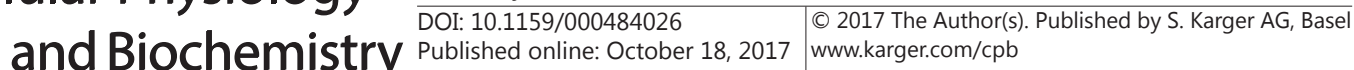 \\ Published online: October 18,2017 with}

mature trabecular bone, a large number of bone cells were visible on the surface by 12 weeks after the operation. BMP is the most useful growth factor with osteoinductive ability [32]. Among the known BMPs, BMP-2 has the most pronounced effect on promoting defect repair and in healing fractures [33]. bFGF, a potent angiogenic factor and bone regeneration factor, induces specialization of MSCs in vitro and bone repair in vivo [17]. bFGF-modified BMSCs could accelerate healing after anterior cruciate ligament (ACL) reconstruction. Furthermore, previous studies have demonstrated the superiority of using gene transfer to deliver multiple growth factors for treating orthopedic diseases such as osteoarthritis and ACL injuries [34, 35]. Thus, it is reasonable for us to hypothesize that the simultaneous gene transfer of BMP2 and bFGF would synergistically achieve more efficient bone repair than either gene alone.

The X-ray imaging results from the 5 test groups indicated that the Ad-BMP-2/bFGF group had the greatest degree of bone regeneration. ONFH reduces blood flow to the femoral head, causing the necrosis of marrow and bone as well as the collapse of the femoral head. These features occur when blood flow is reduced by a mere $20 \%$ or more compared with that found in healthy people [2]. Bone repair is closely connected with the presence of blood vessels in the bone, and bone formation is initiated and supported by these vessels during bone growth [36]. Osteonecrosis is an orthopedic disease caused by diminished blood supply to the bone and will ultimately result in the death of osteocytes and BMCs [37]. Importantly, in the present study, the compressive strength and bending strength in the Ad-BMP2-bFGFGFP group were greater than those of the other groups at 12 weeks after the operation. The DBM, DBM/BMSC, Ad-BMP2-bFGF-GFP and Ad-GFP groups also had greater compressive strength and bending strength than the control group, and the DBM/BMSC, Ad-BMP2-bFGFGFP and Ad-GFP groups had greater strength than the DBM group.

At 6 weeks after the operation, there was little appearance of new bone and incomplete absorption of filler in the DBM and DBM/BMSC groups. However, there was a large amount of new trabecular bone and an increased number of blood vessels in the Ad-BMP2-bFGFGFP group. A previous study showed that expression of the BMP-2 gene was reduced in an exogenous necrosis rabbit model of the femoral head, which indicated that BMP-2 expression strongly impacts the pathogenesis of the femoral head [38]. Another study reported that enhancing bFGF gene expression could be useful for treating osteonecrosis [39].

In summary, our study demonstrated that the application of Ad-BMP-2/bFGF-modified BMSCs combined with DBM could successfully repair ONFH in a dog model by promoting bone formation and angiogenesis. These results provide a new direction for the treatment of ONFH. However, it should be noted that the treatment is still quite complex, and many theoretical and practical problems must still be resolved. The simultaneous delivery of two genes in this study promoted both vascularization and osteogenesis, suggesting that AdBMP-2/bFGF-modified BMSCs offer a new direction for the treatment of ONFH.

\section{Acknowledgements}

We acknowledge the helpful comments received from the reviewers of this paper.

\section{Disclosure Statement}

None.

\section{References}

1 Samy AM: Management of osteonecrosis of the femoral head: A novel technique. Indian J Orthop 2016;50:359-365.

2 Katiella KA, Yanru Z, Hui Z: Magnesium alloy transfected BMSCs-BMP-2 composite in repair of femoral head necrosis with assessment of visceral organs. Springerplus 2016;5:1857. 


\section{Cellular Physiology Cell Physiol Biochem 2017;43:1648-1662 \begin{tabular}{l|l|l} 
and Biochemistry Published onlIne: October 18, 2017 & $\begin{array}{l}\text { (c) } 2017 \text { The Author(s). Published by S. Karger AG, Basel } \\
\text { www.karger.com/cpb }\end{array}$ \\
\hline
\end{tabular}}

Peng et al.: Bmscs Combined with DBM to Repair ONFH

- 3 Ma JH, Guo WS, Li ZR, Wang BL: Local Administration of Bisphosphonate-soaked Hydroxyapatite for the Treatment of Osteonecrosis of the Femoral Head in Rabbit. Chin Med J (Engl) 2016;129:2559-2566.

-4 Tabatabaee RM, Saberi S, Parvizi J, Mortazavi SM, Farzan M: Combining Concentrated Autologous Bone Marrow Stem Cells Injection With Core Decompression Improves Outcome for Patients with Early-Stage Osteonecrosis of the Femoral Head: A Comparative Study. J Arthroplasty 2015;30:11-15.

-5 Sonoda K, Yamamoto T, Motomura G, Nakashima Y, Yamaguchi R, Iwamoto Y: Outcome of transtrochanteric rotational osteotomy for posttraumatic osteonecrosis of the femoral head with a mean follow-up of 12.3 years. Arch Orthop Trauma Surg 2015;135:1257-1263.

-6 Chen C, Qu Z, Yin X, Shang C, Ao Q Gu Y, Liu Y: Efficacy of umbilical cord-derived mesenchymal stem cell-based therapy for osteonecrosis of the femoral head: A three-year follow-up study. Mol Med Rep 2016;14:4209-4215.

7 Lebouvier A, Poignard A, Cavet M, Amiaud J, Leotot J, Hernigou P, Rahmouni A, Bierling P, Layrolle P, Rouard $\mathrm{H}$, Chevallier N: Development of a simple procedure for the treatment of femoral head osteonecrosis with intra-osseous injection of bone marrow mesenchymal stromal cells: study of their biodistribution in the early time points after injection. Stem Cell Res Ther 2015;6:68.

-8 Eaker S, Armant M, Brandwein H, Burger S, Campbell A, Carpenito C, Clarke D, Fong T, Karnieli O, Niss K, Van't Hof W, Wagey R: Concise review: guidance in developing commercializable autologous/patientspecific cell therapy manufacturing. Stem Cells Transl Med 2013;2:871-883.

-9 Wang X, Wang Y, Gou W, Lu Q Peng J, Lu S: Role of mesenchymal stem cells in bone regeneration and fracture repair: a review. Int Orthop 2013;37:2491-2498.

-10 Ren K, Cui H, Xu Q He C, Li G, Chen X: Injectable Polypeptide Hydrogels with Tunable Microenvironment for 3D Spreading and Chondrogenic Differentiation of Bone-Marrow-Derived Mesenchymal Stem Cells. Biomacromolecules 2016;17:3862-3871.

-11 Toupet K, Maumus M, Peyrafitte JA, Bourin P, van Lent PL, Ferreira R, Orsetti B, Pirot N, Casteilla L, Jorgensen C, Noel D: Long-term detection of human adipose-derived mesenchymal stem cells after intraarticular injection in SCID mice. Arthritis Rheum 2013;65:1786-1794.

12 Chung HJ, Hur JW, Ryu KS, Kim JS, Seong JH: Surgical Outcomes of Anterior Cervical Fusion Using Deminaralized Bone Matrix as Stand-Alone Graft Material: Single Arm, Pilot Study. Korean J Spine 2016;13:114-119.

13 Lee JH, Baek HR, Lee KM, Lee HK, Im SB, Kim YS, Lee JH, Chang BS, Lee CK: The effect of poloxamer 407-based hydrogel on the osteoinductivity of demineralized bone matrix. Clin Orthop Surg 2014;6:455461.

14 Lee JH, Kim CS, Choi KH, Jung UW, Yun JH, Choi SH, Cho KS: The induction of bone formation in rat calvarial defects and subcutaneous tissues by recombinant human BMP-2, produced in Escherichia coli. Biomaterials 2010;31:3512-3519.

15 Wang X, Li Y, Han R, He C, Wang G, Wang J, Zheng J, Pei M, Wei L: Demineralized bone matrix combined bone marrow mesenchymal stem cells, bone morphogenetic protein-2 and transforming growth factorbeta3 gene promoted pig cartilage defect repair. PLoS One 2014;9:e116061.

16 Park SY, Kim KH, Shin SY, Koo KT, Lee YM, Seol YJ: Dual delivery of rhPDGF-BB and bone marrow mesenchymal stromal cells expressing the BMP2 gene enhance bone formation in a critical-sized defect model. Tissue Eng Part A 2013;19:2495-2505.

-17 Chen M, Song K, Rao N, Huang M, Huang Z, Cao Y: Roles of exogenously regulated bFGF expression in angiogenesis and bone regeneration in rat calvarial defects. Int J Mol Med 2011;27:545-553.

18 Hu Y, Zhang Q Zhang L, Tang XX, He HY: Basic fibroblast growth factor lentiviral vector-transfected sheep bone marrow mesenchymal stem cells and non-specific osteogenic gene expression. Mol Med Rep 2015;12:267-272.

19 Wang N, Zhang H, Zhang BQ, Liu W, Zhang Z, Qiao M, Zhang H, Deng F, Wu N, Chen X, Wen S, Zhang J, Liao Z, Zhang Q, Yan Z, Yin L, Ye J, Deng Y, Luu HH, Haydon RC, Liang H, He TC: Adenovirus-mediated efficient gene transfer into cultured three-dimensional organoids. PLoS One 2014;9:e93608.

-20 Zhao C, Wu N, Deng F, Zhang H, Wang N, Zhang W, Chen X, Wen S, Zhang J, Yin L, Liao Z, Zhang Z, Zhang Q, Yan Z, Liu W, Wu D, Ye J, Deng Y, Zhou G, Luu HH, Haydon RC, Si W, He TC: Adenovirus-mediated gene transfer in mesenchymal stem cells can be significantly enhanced by the cationic polymer polybrene. PLoS One 2014;9:e92908. 


\section{Cellular Physiology Cell Physiol Biochem 2017;43:1648-1662 \begin{tabular}{ll|l} 
and Biochemistry Published online: October 18, 2017 & $\begin{array}{l}\text { (c) } 2017 \text { The Author(s). Published by S. Karger AG, Basel } \\
\text { www.karger.com/cpb }\end{array}$ \\
\hline
\end{tabular}}

Peng et al.: Bmscs Combined with DBM to Repair ONFH

21 Shi D, Sun Y, Yin J, Fan X, Duan H, Liu N, He W: Cajan leaf combined with bone marrow-derived mesenchymal stem cells for the treatment of osteonecrosis of the femoral head. Exp Ther Med 2014;7:1471-1475.

-22 Fan L, Li J, Yu Z, Dang X, Wang K: Hypoxia-inducible factor prolyl hydroxylase inhibitor prevents steroidassociated osteonecrosis of the femoral head in rabbits by promoting angiogenesis and inhibiting apoptosis. PLoS One 2014;9:e107774.

-23 Kim DH, Lee N, Shin DA, Yi S, Kim KN, Ha Y: Matched Comparison of Fusion Rates between Hydroxyapatite Demineralized Bone Matrix and Autograft in Lumbar Interbody Fusion. J Korean Neurosurg Soc 2016;59:363-367.

-24 Yi J, Lee GW, Nam WD, Han KY, Kim MH, Kang JW, Won J, Kim SW, Noh W, Yeom JS: A Prospective Randomized Clinical Trial Comparing Bone Union Rate Following Anterior Cervical Discectomy and Fusion Using a Polyetheretherketone Cage: Hydroxyapatite/B-Tricalcium Phosphate Mixture versus Hydroxyapatite/Demineralized Bone Matrix Mixture. Asian Spine J 2015;9:30-38.

25 Fu TS, Wang IC, Lu ML, Hsieh MK, Chen LH, Chen WJ: The fusion rate of demineralized bone matrix compared with autogenous iliac bone graft for long multi-segment posterolateral spinal fusion. BMC Musculoskelet Disord 2016;17:3.

26 Choi YS, Kim DH, Park JH, Johnstone B, Yoo JU: Effectiveness of Posterolateral Lumbar Fusion Varies with the Physical Properties of Demineralized Bone Matrix Strip. Asian Spine J 2015;9:433-439.

-27 Park JJ, Hershman SH, Kim YH: Updates in the use of bone grafts in the lumbar spine. Bull Hosp Jt Dis (2013) 2013;71:39-48.

28 Wang X, Li Y, Han R, He C, Wang G, Wang J, Zheng J, Pei M, Wei L: Correction: Demineralized Bone Matrix Combined Bone Marrow Mesenchymal Stem Cells, Bone Morphogenetic Protein-2 and Transforming Growth Factor-beta3 Gene Promoted Pig Cartilage Defect Repair. PLoS One 2015;10:e0125948.

-29 Souza TF, Sakamoto SS, Ferreira GT, Gameiro R, Marinho M, de Andrade AL, Cardoso TC: Osteogenic potential of mesenchymal cells derived from canine umbilical cord matrix co-cultured with platelet-rich plasma and demineralized bone matrix. J Vet Sci 2015;16:381-384.

30 Meng Q, Man Z, Dai L, Huang H, Zhang X, Hu X, Shao Z, Zhu J, Zhang J, Fu X, Duan X, Ao Y: A composite scaffold of MSC affinity peptide-modified demineralized bone matrix particles and chitosan hydrogel for cartilage regeneration. Sci Rep 2015;5:17802.

-31 Pereira-Junior OC, Rahal SC, Lima-Neto JF, Landim-Alvarenga Fda C, Monteiro FO: In vitro evaluation of three different biomaterials as scaffolds for canine mesenchymal stem cells. Acta Cir Bras 2013;28:353360 .

32 Garrison KR, Shemilt I, Donell S, Ryder JJ, Mugford M, Harvey I, Song F, Alt V: Bone morphogenetic protein (BMP) for fracture healing in adults. Cochrane Database Syst Rev 2010;10.1002/14651858.CD006950. pub2CD006950.

-33 Dong Y, Zhang Q, Li Y, Jiang J, Chen S: Enhancement of tendon-bone healing for anterior cruciate ligament (ACL) reconstruction using bone marrow-derived mesenchymal stem cells infected with BMP-2. Int J Mol Sci 2012;13:13605-13620.

-34 Chen B, Qin J, Wang H, Magdalou J, Chen L: Effects of adenovirus-mediated bFGF, IL-1Ra and IGF-1 gene transfer on human osteoarthritic chondrocytes and osteoarthritis in rabbits. Exp Mol Med 2010;42:684695.

-35 Chen B, Li B, Qi YJ, Ni QB, Pan ZQ, Wang H, Chen LB: Enhancement of tendon-to-bone healing after anterior cruciate ligament reconstruction using bone marrow-derived mesenchymal stem cells genetically modified with bFGF/BMP2. Sci Rep 2016;6:25940.

-36 Huang Q Fu Q, Zheng H, Gan M, Wong Y, Chen Z: Establishment of canine models of lunatomalacia through liquid nitrogen freezing. Exp Ther Med 2013;5:880-884.

37 Lin YC, Chen WS, Chang CC, Chen M, Yu CT: Aseptic necrosis of bilateral femoral heads after pregnancy. Taiwan J Obstet Gynecol 2011;50:111-113.

38 Sun NRG, Liu FA: Experimental study on the expression of VEGF and BMP-2 in steroid-induced osteonecrosis of the femoral head. 2013;10:2853-2857.

-39 Guo X, Zheng Q, Kulbatski I, Yuan Q Yang S, Shao Z, Wang H, Xiao B, Pan Z, Tang S: Bone regeneration with active angiogenesis by basic fibroblast growth factor gene transfected mesenchymal stem cells seeded on porous beta-TCP ceramic scaffolds. Biomed Mater 2006;1:93-99. 